\title{
Memory scanning for words in visual images
}

\author{
LEE D. ROTHSTEIN and RICHARD C. ATKINSON \\ Stanford University, Stanford, California 94305
}

\begin{abstract}
This study attempts to replicate an experiment reported by Seamon (1972). In the present investigation, as in the study by Seamon, the scanning of short-term memory was compared when its contents were rehearsed words vs. a mental image. Memory sets were composed of either one, two, or three words. In the relational imagery group, subjects were required to form a single interactive mental scene of the entities which the memory set words represent. Nonimagery subjects were given instructions to covertly rehearse the memory set. In both groups, the usual memory set size (m) effect was obtained, i.e., reaction time (RT) increased linearly with $\mathrm{m}$. Moreover, the set size effect was the same for both groups. This latter finding stands in marked contrast to the result obtained by Seamon; he found no effect of set size when subjects were given interactive imagery instructions. Because of the failure to replicate Seamon, an additional group of subjects were given imagery instructions. For this latter group, some of the procedural discrepancies between the relational imagery group of the present study and the corresponding group in Seamon's study were resolved. Also, in this additional group, the set size effect was examined as a function of the subjects' ratings of the quality of the images which they had formed. The same set size effect was found for this additional group, and the effect was independent of image quality.
\end{abstract}

In Sternberg's (1966) item recognition task, a small set of stimuli (the memory set) is presented to the subject. Following the memory set, the subject sees a probe (or test stimulus). If the test stimulus is a member of the memory set, the subject is to make a yes response; otherwise, a no response. Sternberg obtained a linear function for the relationship of reaction time (RT) to memory set size (m) (cf. Briggs, 1974), and concluded that subjects were engaging in a serial search process (or scan), i.e., subjects were sequentially comparing an encoding of the test stimulus against the internal representations of the items in the memory set. Because the slopes of the RT vs. $m$ functions were identical for both yes and no responses (cf. Clifton \& Birenbaum, 1970; Kristofferson, 1972), Stemberg further concluded that the scan was exhaustive, i.e., subjects compared the probe against all items in the memory set, even if the probed matched an item before the last item of the set (cf. Anderson, 1973; Baddeley \& Ecob, 1973; Briggs, 1974; Cavanagh, 1972; Corballis \& Miller, 1973; Theios, Smith, Haviland, Traupman \& Moy, 1973). In the hundreds of studies that have followed Sternberg's (1966) initial efforts, the monotonic increase of RT with $\mathrm{m}$ has proven to be a reliable and substantial effect (Briggs, 1974; Egeth, Marcus, \& Bevan, 1972; Nickerson, 1972).

Recently, Seamon (1972) has presented some data where RT does not increase with $\mathrm{m}$, but instead remains constant. Seamon defined memory sets of either one, two, or three words on each trial for subjects in each of three groups. In a control group, the "nonimagery group," subjects were given instructions to subvocally

This research was supported by a grant from the National Institute of Mental Health (MH-21747). Requests for reprints should be sent to Professor Richard C. Atkinson. Department of Psychology, Stanford University, Stanford, California 94305. rehearse the memory set prior to the presentation of the test stimulus. In the "separate imagery group," subjects were told to form separate, noninteracting images of the entities that the words in the memory set represent. Subjects in the "relational imagery group" were also told to form images for each of the words; however, these subjects were required to combine the images into a single interactive scene. Results for the nonimagery and separate imagery groups were quite similar; the slope of the RT vs. $m$ function for the nonimagery group was $48 \mathrm{msec} /$ memory set item, whereas the slope for the separate imagery group was $44 \mathrm{msec} / \mathrm{item}$. In contrast, the set size effect of the relational imagery group did not differ significantly from zero; the slope of the RT vs. $m$ function was 4 msec/item.

On the basis of these results, Seamon (1972) concluded that the memory codes for rehearsed and separately imaged words required a sequential comparison process, whereas words represented in a visually imaged scene could be processed in parallel. This interpretation is consistent with Paivio's (1971, see especially pp. 33-37) theorizing that the visual system is a parallel processing system in contrast to the verbal system which is essentially sequential in nature.

We were intrigued by Seamon's results and wished to pursue this line of research. We thought it best, however, to begin by replicating Seamon's basic result-the absence of a set size effect under interactive imagery instructions.

In our attempt at replication, we employed only the nonimagery and relational imagery groups. While we reduced the number of groups, we increased the power of the design by having four times the number of subjects per group and one-third more trials per subject than Seamon. 


\section{METHOD}

\section{Subjects}

Forty-eight right-handed undergraduates at Stanford University served as subjects. The subjects were a mixture of volunteers paid $\$ 2.50$ and introductory psychology students who were fulfilling course requirements. Subjects were randomly assigned to the two groups.

\section{Procedure}

Nouns were selected from the Paivio, Yuille, and Madigan (1968) norms within the following constraints: (a) the words were easily imageable, i.e., they had I values of 6.30 or greater; (b) the words were highly concrete, i.e., they had $\mathrm{C}$ values of 6.00 or greater; (c) they were common nouns, i.e., they had Thorndike-Lorge frequencies of one per million or greater; (d) they had between three and eight letters so that recognition could not be based on word length; (e) in order that images could be formed unambiguously and as whole entities, collective nouns and body parts were eliminated. Using these criteria, a total of 108 words were selected to form the pool for the experiment. A comparison of the word pool of the present experiment with the pool employed by Seamon (Reference Note 1) reveals considerable overlap of words, and no obvious differences in the characteristics of the two pools.

Memory sets were composed of one, two, or three words. Because we wished subjects to form vivid images and because so few words met the above criteria, each memory set was used for eight consecutive trials. Words were sampled randomly and without replacement from the pool to form memory sets and to select negative probes. Thus, each word served only once in the experiment as a memory set item or as a negative probe for any single subject. The words selected as positive probes did, of course, occur more than once. Their first occurrence was as members of the memory set. They occurred again as test stimuli as often as was required by the size of their memory set and the number of positive responses required during the eight trials for which the memory set was employed. Across the eight trials, for positive probes, the words of the memory set were sampled, as much as was possible, equally often.

Two sets of 144 trials were employed in the experiment. Half of the subjects in each group received each of the sets. The assignment of words to memory sets and negative probes were different for the two sets. Each subject received a different randomization of one of the sets. Randomizations of sets were accomplished within the following constraints: (a) the blocks of eight trials, each of which was associated with a particular memory set, were the same across all of the randomizations of each of the sets; (b) within a set of 72 consecutive trials, all combinations of set size and response occurred equally often; (c) within a block of eight trials, no more than three trials in a row, nos more than a total of five trials could be of the same response; (d) each consecutive set of three eight-trial blocks contained one block each of the three set sizes.

Memory sets for each block of eight trials were read to the subject prior to the block. Each test stimulus was typed in capital letters on a plain white $6 \times 9$-in. $(2.36 \times 3.54 \mathrm{~cm})$ index card with an IBM Executive Registry typewriter. Test stimuli were presented in an Iconix 6137 tachistoscope.

After the experimenter said, "Ready," the subject initiated a trial by pressing a button which he held in his left hand. On a table slightly to the right of the subject were three telegraph keys arranged in an arc. Each key was $2.8 \mathrm{~cm}$ in diam. Adjacent keys were $.5 \mathrm{~cm}$ apart. The subject was told to rest his right index finger on the center key at the start of a trial and to respond yes by pressing the key on his right or no with the key on his left. RT was measured from the onset of the test stimulus to the completion of the subject's response by an Iconix 6255 time base counter.

A session took approximately 40 min. At the start of a session, the experimenter gave all subjects the same practice instructions. The instructions emphasized that subjects were to respond as quickly as possible without making errors. For practice trials, just as for experimental trials, memory sets served for eight consecutive trials. Subjects were told that prior to a block of eight trials, they would be given a memory set of one, two, or three digits. Subjects were not given instructions on how to memorize the memory set during practice so that practice would be equivalent for the two groups. The subject then received 24 practice trials, one eight-trial block for each of the three set sizes. The sequence of events for practice (with the exception of imagery instructions) was the same as for experimental trials. The experimenter read the memory set to the subject prior to a block of eight trials. He then put a test stimulus into the tachistoscope and said, "Ready." The subject, at his convenience, pressed the button in his left hand to initiate the presentation of the probe. After the subject's button press, a warning $X$ appeared in the scope followed 500 msec later by the probe. The experimenter recorded the RT for the trial, removed the probe from the scope, and began the next trial.

Following practice, subjects were given instructions peculiar to their group. Nonimagery group subjects were told that the stimuli for experimental trials were going to be words. These subjects were further told that they were to covertly rehearse the words on each trial prior to seeing the test stimulus. Relational imagery group subjects were told to create a mental scene of the individual images for each of the words. Subjects were told that the scene must be interactive, i.e., each of the imaged entities of the scene must be taking a part complimentary to the theme of the scene. After forming the interactive mental image, the subject was required to describe it to the experimenter before starting the block of eight trials. The description was required to make sure that the subject was following instructions. The subject was always given as much time as he needed to form the mental scene. The subject was told to "refresh" the image before the presentation of the test stimulus of the first trial of the eight-trial block and was also reminded to refresh the image several times during a block. On any trial on which the subject felt that he had "lost the image prior to responding, he was to tell the experimenter immediately after responding.

\section{RESULTS AND DISCUSSION}

Figure 1 presents a summary of the basic results of the experiment. Mean RT is plotted as a function of memory set size for yes and no responses for each group; the corresponding error rates are given at the bottom of the figure. The data upon which Figure 1 is based do not include a total of five trials across all subjects and types which were eliminated for the relational imagery group, because the subject reported that he had lost the image prior to responding. This is the same procedure as used by Seamon. (Seamon deleted fewer than $2 \%$ of all trials on this basis.) The means of RTs for correct responses were analyzed using a factorial fixed-effects analysis of variance (ANOVA).

As can be seen in Figure 1, there was a marked overall effect of set size, $F(2,88)=344.25, p<.0001$, and response, $F(1,44)=60.89, p<.0001$. The marked effect of response reflects in part the assignment of the right key for right-handed subjects to the yes response. The overall effect of set size and the lack of a significant interaction of set size and groups (nonimagery vs. relational imagery), $F(2,88)=1.33, p>.20$, implies that 


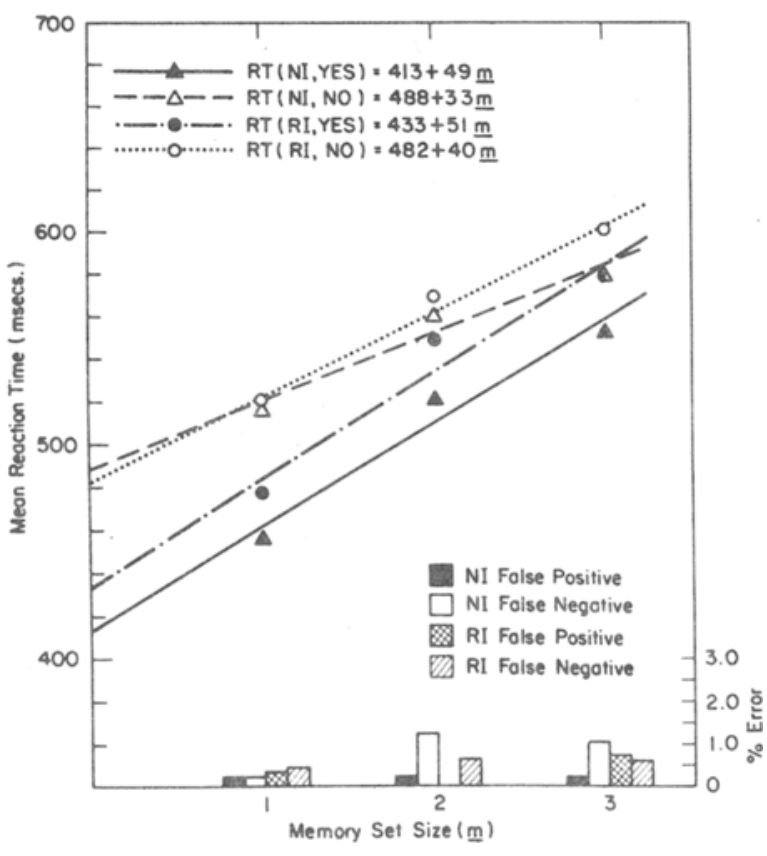

Figure 1. Mean RT as a function of set size (m) for yes and no responses for the nonimagery (NI) and relational imagery (RI) groups.

the slopes of the RT vs. $\mathrm{m}$ functions for the two groups are the same.

One last effect remains to be described. There is a difference in the slopes of the RT vs. $m$ functions across response. Consistent with this difference, the Set Size by Response interaction is statistically significant, $\mathrm{F}(2,88)=11.41, \mathrm{p}<.0002$. This relationship of no responses having a lesser slope than yes responses has been obtained previously when the stimuli are words and negative probes are not repeated. (The result and an explanation are provided in Atkinson and Juola, 1974.)

There are several differences in procedure between the present study and the investigation by Seamon (1972). In a discussion of our results with colleagues who are well versed in imagery research, two of these differences emerged as possible causes for the differences in results between our study and the study by Seamon. First, subjects in our relational imagery group first participated in practice trials in which a strategy of covert rehearsal may have been adopted. Once having adopted a rehearsal strategy, subjects may continue with it even though they are later given imagery instructions. Second, our instructions did not stress that subjects were to look for the probe word in the mental scene as Seamon's instructions had done. Instructions to look for the probe in the image stress the importance of using the image in the decision making process. A failure to use the image may produce the set size effect in our relational imagery group.

Because of differences in procedure, we decided to run another group of eight subjects using relational imagery instructions. The method for this additional group was the same as for the first relational imagery group, except for the following differences. All practice was omitted. The phrase "memory set" was not used in the instructions to subjects to avoid encouraging rehearsal. Subjects were told to create an interacting mental scene of the words read to them by the experimenter. They were further told to look for the presence of the image of the test word within the mental scene which they had formed. We also added a manipulation in order to assess the effects of image quality on scanning. We requested subjects to describe "the goodness of the mental scene," i.e., "how easy was it to keep in mind?" on a 5-point scale.

Figure 2 presents a summary of the data of the additional group of eight subjects. Again, as in the first group, there are marked effects of set size, $F(2,14)=52.71, \quad p<.0001 ;$ and response, $F(1,7)=22.85, p<.005$. Surprisingly, the Set Size by Response interaction obtained with the first two groups was not significant for the additional group, $F(2,14)<1.0$. These results replicate the set size effect obtained in the first group given interactive imagery instructions.

An additional statistical analysis was performed on the data. RT was examined as a function of rated image goodness. For each subject within each set size, RTs were divided into those generated on trials on which the imagery value was above the median and those RTs given on trials on which the image value was below the

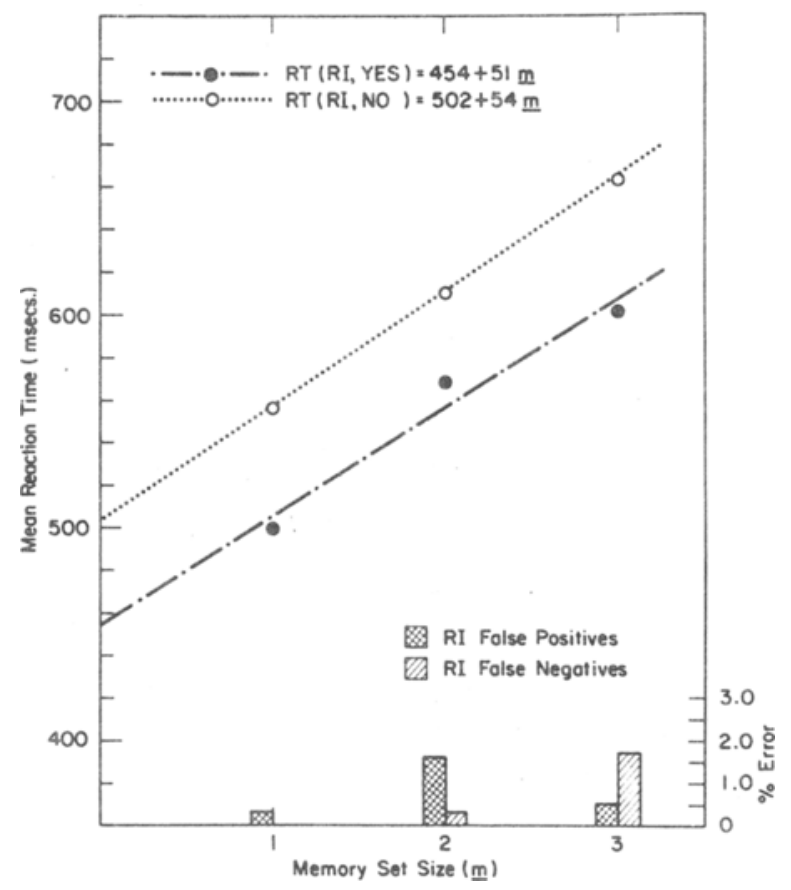

Figure 2. Mean RT as a function of set size for yes and no responses for the additional relational imagery (RI) group. 
median. It was necessary to do the median split within set size in order to have high and low imagery values for each set size. This was necessitated by the fact that average image goodness varied inversely with $\mathrm{m}$.

With the addition of the imagery value distinction, an ANOVA was run on mean RT. While there was an overall facilitory effect $(23 \mathrm{msec})$ of high vs. low image goodness, $F(1,7)=8.21, p<.025$, image goodness did not interact with set size, $F(2,14)=1.08$. The set size effect in the additional group, then, does not seem to depend upon the subject's rating of the quality of the mental image.

We have made a concerted effort to replicate Seamon's experimental findings without success. It is possible that there are differences between our situation and his that account for the failure to reproduce the original findings, but we have no idea what they may be. We are inclined to conclude that the differences in results are either due to a lack of reliability in Seamon's study or possibly a difference in demand characteristics between the two studies unrelated to imagery instructions.

\section{REFERENCES}

Anderson, J. A. A theory for the recognition of items from short memorized lists. Psychological Review, 1973, 80, 417-438.

Atkinson, R. C., \& Juola, J. F. Search and decision procesess in recognition memory. In D. H. Krantz, R. C. Atkinson, R. D. Luce, and P. Suppes (Eds.), Contemponary developments in mathematical psychology (Vol. 1). San Francisco: Freeman, 1974.
Baddeley, A. D. \& Ecob, J. R. Reaction time and short-term memory: Implications of repetition effects for the high-speed exhaustive scan hypothesis. Quarterly Joumal of Experimental Psychology, 1973, 25, 229-240.

Briggs, G. E. On the predictor variable for choice reaction time. Memory \& Cognition, 1974, 2, 575-580.

Cavanaqh, J. P. Relation between the immediate memory span and the memory search rate. Psy chological Review, 1972, 79, 525-530.

Clifton, C \& Birenbaum, S. Effects of serial position and delay of probe in a memory scan task. Journal of Experimental Psychology, 1970,86, 69-76.

Corballis, M. C.. \& Miller, A. Scanning and decision processes in recognition memory. Journal of Experimental Psychology, $1973,98,379-386$.

Egeth, H., Marcus, N., \& Bevan, W. Target-set and response-set interaction: Implications for models of human information processing. Science, 1972, 176, 1447-1448.

Kristofferson, M. W. When item recognition and visual search functions are similar. Perception \& Psychophysics, 1972, 12, 379-384.

Nickerson, R. S. Binary-classification reaction time: A review of some studies of human information-processing capabilities. Psychonomic Monograph Supplements, 1972, 4, Whole No. $65,275-318$.

Paivio, A. Imagery and verbal processes. New York: Holt, Rineh art, and Winston, 1971.

Paivio, A., Yuille, J., \& Madigan, S, Concreteness, imagery and meaningfulness value for 925 nouns. Joumal of Experimental Psy chology, 1968, 76, Monograph Supplement, No. 1, Part 2. Seamon. J. G. Imagery codes and human information retrieval. Journal of Experimental Psychology, 1972, 96, 468-470.

Sternberg. $S$. High-speed scanning in human memory. Science, $1966,153,652-654$

Theios, J., Smith, P. G., Haviland, S. E., Traupman, J., Moy, M. C. Memory scanning is a serial, self-terminating process. Journal of Experimental Psychology, 1973, 97, 32 3-336.

\section{REFERENCE NOTE}

1. Seamon, J. G. Personal communication, September 1974.

(Received for publication October 26, 1974; accepted December 1,1974 .) 